\title{
Periscope
}

\section{SYMPTOMATOLOGY OF A GROUP OF FRONTAL LOBE LESIONS.}

The recognition of frontal lobe lesions, particularly on the right side, offers unusual difficulties owing to the fact that such lesions often cause only slight symptoms, and the so-called classic symptoms are often not observed. The symptoms usually emphasised are the emotional changes, eye-ground changes, particularly primary optic atrophy on the side of the lesion, with choked disc on the opposite side, unilateral tremor of the hand and arm on the same side, loss of the abdominal reflex on the opposite side, anosmia on one or both sides, and speech disturbances.

The author describes 25 cases, of which ro were gliomata, 7 endotheliomas, 2 gummas, 2 abscesses, I arachnoidal cyst, I chronic inflammatory mass around a foreign body, I basal cell carcinoma and I degeneration. The symptoms are analysed, and it is pointed out that two symptoms have stood out more prominently than any others and can be depended on more than any of the so-called classical symptoms. These are (I) slight weakness of the lower portion of the face, that part innervated by the two lower branches of the facial nerve on the side opposite the lesion. It is not an emotional disturbance, nor necessarily demonstrable by voluntary movement. It is usually most obvious during conversation and is no doubt a pressure phenomenon involving the highly specialiser face centre. It was noticed in 20 of the 25 cases. (2) The second and leading symptom is the mental change which is quite characteristic and distinct. Patients become peculiarly indifferent, have no realisation of the seriousness of their condition, are not euphoric, show loss of memory for recent events, and neglect their work. This mental disturbance when present and unchanged for some time, and associated with some facial weakness and headache, in the absence of a positive Wassermann reaction, indicates a frontal lobe lesion and entitles the patient to an exploration. ERNEST SACHS (Brain, 1927, 1., 474-487).

A. N. B.

\section{THE MECHANISM OF CICATRICIAL CONTRACTION IN THE BRAIN.}

It is well known that injury to the surface of the brain following fracture of the skull may be later followed by epilepsy. This is due to the formation of meningo-cerebral adhesions. The author has investigated here the principles which underlie the process of woundhealing in the brain, and discusses the factors involved in cicatricial contraction with special reference to certain misconceptions responsible for many of the hitherto proposed cranioplastic operations for Jacksonian epilepsy. 


\section{Periscope}

The pia mater serves as a delicate capsule dipping into all the crevasses of the brain, but there are no connective tissue septa in it. In place of septa is the vascular tree which ramifies in the pia and penetrates perpendicularly into the nervous tissue. The structural connection between vessels and nervous tissue is by neuroglia astrocytes. These octopus-like astrocytes have usually many perivascular attachments or "sucker-feet" and contain fibres. They hold the manifold structures of the nervous system within their tentacles, and being attached to both pia and vascular tree by such specialised expansions, form the supporting frame-work of the adult nervous system, the socalled vaso-astral framework. The brain is usually seen to pulsate beneath the dura when a craniotomy is performed. This pulsation takes place partly in the subdural space which is an actual space and normally contains a thin layer of yellowish fluid. This subdural space may thus be likened to the pleural, pericardial, and peritoneal spaces. Incision or removal of dura mater without injury to arachnoidea results in the regeneration of dura with little or no adhesion between the two membranes. Injury to the pia-arachnoid results in the formation of an adhesion, as such injury breaks the barrier formed by the avascular arachnoid and removes the protective covering of the nervous system. Such a break calls forth an energetic connective tissue response and thus allows an anastomosis to form between the meningeal and the cerebral blood-vessels. The amount of adhesion varies directly with the amount of injured cerebral tissue left behind. A stab wound in the brain is followed by a connective tissue adhesion of such strength that at autopsy a core may be withdrawn from the wound tract by the firmly attached dura. If the injured tissue, however, be removed by using a hollow needle to ream out a cylinder of brain no connective tissue core is formed, and the surface adhesion is slight. Blood-clots form in both instances, but in the first case a mass of newly-formed connective tissue forms with anastomosis between the meningeal and cerebral vessels. All such connective tissue scars contract, and thus the cerebral vessels are drawn through the pia into the overlying scar with sub sequent tension on the vaso-astral framework. In the second place, where the injured cerebral tissue has been removed, no connective tissue core is formed and a gaping hole is left in the brain substance, the blood-clot being later replaced by fluid.

In large wounds with much brain destruction the scar formation is correspondingly extensive, and the resultant traction may be very great. Owing to the consistency of brain tissue there can be little resistance to such contraction, and distortion of the brain occurs. This may pull the lateral wall of the lateral ventricle towards the scar, and even cause deflection of both ventricles towards that side.

Cerebral cicatrix may thus be largely avoided if injured brain tissue

$\begin{array}{lll}\text { VOL. XXXV. NO. XI. } & 653 & 2 \mathrm{U} 2\end{array}$ 


\section{Periscope}

be removed completely and the removal be not too superficial. There then results a gaping hole which is filled with blood-clot and which soon seems to be replaced by fluid. Embolism not infrequently produces similar fluid-filled spaces.

In brain surgery operations which leave brain wounds full of foreign material defeat their purpose at the start as such foreign matter, which includes brain debris, produces a violent foreign body reaction. To eliminate cicatricial contraction and provide for formation of a fluidfilled space with a minimum of adhesion all injured brain tissue must be removed, or the old scar excised, while the defect in the skull is closed, thus leaving a dead space filled with fluid. A contracting scar will in the long run ultimately destroy more brain tissue than the initial removal would have done, and in addition the slow contraction of such a scar, continuing for years, must produce a constant irritation which may well be a starting point for a nervous discharge resulting in Jacksonian epilepsy. Clean excision of such a cicatrix should convert a contracting scar into a fluid-filled space and relieve the remainder of the brain from abnormal traction.

W. Penfield (Brain, I927, 1., 499-5 I 7).

A. N. B.

\section{ABDOMINAL LITHOPÆDION SIMULATING AN OVARIAN TUMOUR.}

M. Chevrier reports the case of a woman who came to hospital complaining of two abdominal tumours, one behind the other. They were of large size, very hard, painless, and relatively mobile and distinct from the uterus. They appeared to be a double ovarian tumour. She gave a history of believing herself pregnant three years ago and that several doctors whom she had consulted were of the same opinion. When, however, her confinement was due nothing happened. Her abdomen became rather smaller and menstruation which had been absent reappeared. On cœliotomy the tumour was found very adherent. The right ureter had been displaced by the tumour to the left side where it was at first mistaken for the left ureter. On examination of the tumour it was found to consist of a mummified full-time female fotus. The limbs were intact except that one fibula was denuded of its soft structures and fractured towards its proximal end. There was no amniotic fluid and the mass weighed $5 \mathrm{lb}$. Inspection of the uterus and tube at operation did not show evidence of the pregnancy having been originally tubal.

L. Chevrier, "Fœtus à terme momifié datant de deux ans et demi pris pour une double tumeur solide de l'ovaire" (Bull. et mém. de la soc. nat. de chirurg., Paris, 1928, liv., 223 ). 